\title{
Effect of saliva composition and flow on inter- individual differences in the temporal perception of retronasal aroma during wine tasting
}

\author{
Celia Criado, Carolina Chaya, Virginia Fernández-Ruíz, María Dolores Álvarez, \\ Beatriz Herranz, María Ángeles Pozo-Bayón
}

\begin{abstract}
A B S T R A C T
In order to determine if inter-individual differences in saliva composition and flow influence the perception of specific aromatic stimuli elicited by esters after wine consumption, ten individuals were selected and instructed in the recognition of four aromatic stimuli elicited by four ester compounds, which were added to a rosé wine. The whole panel was firstly characterised by their salivary flow, composition ( $\mathrm{pH}$, total protein content, macroand micro- minerals) and rheological properties (viscosity), and secondly, the panellists were trained in a dynamic sensory method for the evaluation of retronasal aroma intensity at discrete time intervals $(5,60,120$, and $180 \mathrm{~s})$ after wine expectoration. Significant inter-individual differences $(p<0.05)$ in saliva composition were found in most salivary parameters. Differences in the intensity ratings among individuals were also found for the four aroma attributes. Spearman correlation analysis between saliva parameters and aroma intensity over time showed a strong positive correlation between salivary flow and aroma perception for some aroma and time points. This correlation was higher in the immediate than in the long lasting perception and greater for aroma attributes elicited by short chain length esters (isoamyl acetate, ethyl butanoate and ethyl hexanoate) (than for attributes elicited by larger esters (ethyl decanoate).
\end{abstract}

\section{Introduction}

Olfactory receptors are located in the nasal cavity and the perception of aroma compounds during eating and drinking requires their release into the mouth and their transport to the receptors via retronasal (Canon, Neiers, \& Guichard 2018). Different factors affect aroma release during food or beverage intake. Some are inherent to the specific food matrix, such as the chemical characteristics of the volatile compounds (volatility, polarity, hydrophobicity, etc.) and the physicochemical properties of the food matrix (chemical composition, physical properties, texture, viscosity, etc.) (Ployon, Morzel, \& Canon 2017). As well as these above-mentioned factors, the release of aroma compounds in the mouth during eating or drinking also depends on oral processing and oral physiology (Linforth \& Carey 2002).

In this regard, saliva might have a large impact on aroma perception, as it controls the dynamic release of odorants from the mouth to the olfactory receptors in the nose. For instance, saliva can affect the adsorption of odorants onto the mouth surfaces (i.e. oral mucosa), their metabolism by enzymatic modification, and the friction force in the oral cavity (Canon et al. 2018). In addition to the saliva freely circulating in the mouth, a thin layer of salivary proteins, called the mucosal pellicle, covers the epithelium. Aroma compounds can adsorb directly onto it and/or on the product coating covering the mouth and pharyngeal mucosa once the food or beverage has been swallowed, which can be largely responsible for the dynamic profile of aroma release (Buettner, Beer, Hannig, \& Settles 2001). Thus, the effect of saliva might not only be in the immediate aroma perception after swallowing but also on the prolonged aroma perception or aroma persistence (Ployon et al. 2017).

The wide array of effects of saliva on aroma compounds highlights the idea that differences in saliva composition might reflect differences in aroma release and in aroma perception. Nonetheless, very little research and no clear direct links have been established between salivary composition and aroma perception (Muñoz-González et al. 2018).

In the case of wine, in which aroma plays a definitive role on consumer's preferences and choices, scientific works regarding the effect of saliva on aroma are very scarce. In pioneer studies, using static and/or 
dynamic headspace conditions, important differences in the amount of aroma released when using human saliva compared to synthetic saliva (Muñoz-González et al. 2014); Genovese, Piombino, Gambuti, \& Moio 2009 were found.. The influence of the individual on the kinetics of aroma release using -in vivo conditions was observed by Esteban-Fernandez and co-authors (Esteban-Fernández, Rocha-Alcubilla, MuñozGonzález, Moreno-Arribas, \& Pozo-Bayón 2016), although the link between these results with differences in oral physiology was not considered in this work. More recently, a relationship between some compositional saliva parameters, and the in-mouth release of some aroma compounds, has been established by using -in vivo conditions (Muñoz-González, Canon, Feron, Guichard, \& Pozo-Bayón 2019; PerezJiménez, Chaya, \& Pozo-Bayón 2019).

However, as stated in a recent review on this topic, the relationship between saliva composition and -in vivo aroma release might not be enough to explain aroma perception due to the coexistence of physicochemical and complex brain processing mechanisms of the sensory signals (Guichard, Repoux, Qannari, Labouré, \& Feron 2017). Thus, it is also necessary to investigate the role of saliva composition considering its impact on sensory perception.

In this sense, Neyraud and co-workers (Neyraud, Palicki, Schwartz, Nicklaus, \& Feron 2012) showed a high inter-individual variability in saliva composition, which was linked to differences in fatty perception. It has also been described that human subjects with high salivary sodium concentrations are less sensitive to saltiness (Guichard et al. 2017). Differences in saliva flow rate have been previously related to differences in some gustatory attributes such as the perceived intensity of bitterness and astringency (Fischer, Boulton, \& Noble 1994) or acid tastes (Guinard et al. 1997). Regarding aroma perception, the sodium content in saliva could also be related to differences in cheese aroma perception (Guichard et al. 2017).

Despite the limited number of works regarding the effect of saliva on aroma perception, these previous evidences seem to indicate that inter-individual variation in saliva composition might be of importance in explaining differences in individual aroma perception, which in the case of wine, has not been addressed yet.

Therefore, considering the above mentioned evidences and the lack of studies in this topic, the aim of this work was to determine the relationship between individual differences in saliva composition and the perception of different aroma stimuli elicited by some typical wine carboxylic esters associated to the pleasant and fruity character of many wine types (Escudero, Campo, Fariña, Cacho, \& Ferreira 2007; Francis \& Newton 2005; Rapp \& Mandery 1986). For this study, a rosé wine was aromatized with four esters (isoamyl acetate, ethyl butanoate, ethyl hexanoate and ethyl decanoate) to reinforce its aromatic profile with four different aroma descriptors ("banana", "strawberry flavoured sweet", "pineapple" and "dried plum"), which were previously selected by a volunteer panel $(n=10)$. The chemical, biochemical (saliva flow, $\mathrm{pH}$, total protein content) and rheological characterisation (viscosity) of the stimulated saliva collected from all the volunteers was carried out. In addition to this, the panel was trained in the recognition and rating of the retronasal aroma intensity of these descriptors at different times after rinsing and spitting out the wine by using a dynamic sensory methodology (progressive profiling). Spearman correlation analysis and regression analysis were applied in order to determine the relationship between saliva compositional parameters and the perceived aroma intensity of the four descriptors at discrete times $(5,60,120$, and $180 \mathrm{~s})$ after wine expectoration.

\section{Experimental}

\subsection{Saliva collection}

For this study, 10 healthy non-smoker volunteers ( 4 males, 6 females) between 18 and 36 years old were recruited on the basis of their interest in the study. They were recruited for saliva donation the week before the sensory study. One hour before saliva collection, volunteers were not allowed to drink or to eat. They were also instructed to brush their teeth and vigorously rinse their mouths with tap water. Stimulated saliva was collected directly in a sterile tube (previously weighed). The subjects were told to avoid swallowing during the saliva collection process. The subjects chewed a piece of Parafilm ${ }^{\mathrm{TM}}$ and spat their saliva into the tube as many times as they wanted for $5 \mathrm{~min}$. This stimulates both parotid and submandibular/sublingual glands that contribute $60 \%$ and $40 \%$ respectively to the whole salivary flow. This is an acknowledged saliva collection procedure representative for the entire salivary protein secretion pattern (Dinnella, Recchia, Fia, Bertuccioli, \& Monteleone 2009). Saliva flow was calculated from the weight of saliva, and expressed as $\mathrm{mg} / \mathrm{mL}$ assuming $1 \mathrm{~g}$ being equal to $1 \mathrm{~mL}$, as is commonly done in studies involving salivary flow measurements One part of saliva from each individual was separated to perform the rheological measurements. The rest of the saliva samples were clarified by centrifugation at $15000 \mathrm{~g}$ for $15 \mathrm{~min}$ at $4{ }^{\circ} \mathrm{C}$, which allowed the removal of bacteria and cellular debris. Subsequently, $200 \mu \mathrm{l}$ of the supernatants were taken in order to measure the $\mathrm{pH}$ of the saliva. This was carried out with a pH meter (CP-505, ELMETRON). No > 10 min elapsed between saliva collection and centrifugation. During this time they were kept in ice. To avoid any possible deterioration of the samples before their analyses, the centrifuged saliva was divided into $1.5 \mathrm{~mL}$ aliquots using a sterile Eppendorf and stored at $-80^{\circ} \mathrm{C}$. All the analytical determinations were performed in centrifuged saliva. Only rheological measurements were performed in non-centrifuged saliva. These saliva samples were also stored at $-80^{\circ} \mathrm{C}$ until their analysis.

\subsection{Saliva analysis}

\subsubsection{Protein concentration}

Total protein content (TPC) was measured using the commercial kit Pierce ${ }^{\mathrm{TM}}$ BCA Protein Assay Kit (Pierce Thermo Scientific, Illinois, USA) with bovine serum albumin as the calibration standard.

\subsubsection{Mineral composition. Macro ( $\mathrm{Na}, \mathrm{K}, \mathrm{Ca}, \mathrm{Mg}$ ) and microelements} (Zn)

Mineral element analysis was performed on the samples based on the method 930.05 of the AOAC (Official Methods of Analysis). Na, K, $\mathrm{Ca}, \mathrm{Mg}$ and $\mathrm{Zn}$, were quantified by atomic absorption spectroscopy (AAS) using the Analyst 200 Perkin Elmer equipment (Perkin Elmer, Waltham, MA, USA). Briefly, $0.5 \mathrm{~mL}$ of each sample of saliva was made up to an appropriate volume with distilled water $(5 \mathrm{~mL})$ where $\mathrm{Zn}$ was directly measured. An additional 1/10 $(v / v)$ dilution of the sample fraction and standards was performed using macroelement determination: for $\mathrm{Ca}$ and $\mathrm{Mg}$ analysis in $1.16 \%(w / v) \mathrm{La}_{2} \mathrm{O}_{3} / \mathrm{HCl}$ (leading to $\mathrm{LaCl}_{2}$ ); and for $\mathrm{Na}$ and $\mathrm{K}$ analysis in $0.2 \%(\mathrm{w} / \mathrm{v}) \mathrm{CsCl}$ (Ruiz-Rodríguez et al. 2011). All measurements were performed by AAS with air/acetylene flame in Analyst 200 Perkin Elmer equipment (Perkin Elmer, Waltham, MA, USA), comparing absorbance responses with $>99.9 \%$ purity analytical standard solutions for AAS made with $\mathrm{Zn}\left(\mathrm{NO}_{3}\right)_{2}$, $\mathrm{NaCl}, \mathrm{KCl}, \mathrm{CaCO}_{3}$ and $\mathrm{Mg}$ band. The results were expressed in $\mathrm{mg}$ per $\mathrm{L}$ of saliva. Zn, was provided by Merck (Darmstadt, Germany) and the rest of the chemicals used for the analyses were obtained from Sigma-Aldrich (Steinheim, Germany).

\subsubsection{Saliva rheology}

The viscosity was measured in a rotational Kinexus pro rheometer (Malvern Instruments Ltd., Worcestershire, UK). The rheometer was equipped with a $40 \mathrm{~mm}$ cone $\left(1^{\circ}\right)$ and plate geometry with a gap of $0.150 \mathrm{~mm}$. Temperature was controlled to within $0.1^{\circ} \mathrm{C}$ by Peltier elements in the lower plate and kept at $37^{\circ} \mathrm{C}$. One $\mathrm{mL}$ of non-centrifuged saliva was placed onto the plate. To homogenise mechanical equilibrium before measurements, a pre-shearing test was carried out for one $\min$ at $100 \mathrm{~s}^{-1}$. The flow curves were obtained as a function of logarithmic shear rate ramp using a down ramp from 100 to $0.01 \mathrm{~s}^{-1}$ with 5 
measurements per second. Data from the flow curves were fitted to the power law or Ostwald de Waele model $\left(\eta=K \dot{\gamma}^{n-1}\right)$, where $\eta$ (Pa s) is the apparent viscosity, $K\left(\mathrm{~Pa} \mathrm{~s}^{\mathrm{n}}\right)$ is the consistency index and $n$ is the flow index. For statistical analysis of the flow curves, viscosity at a shear rate of $50 \mathrm{~s}^{-1}$ was also taken. This shear rate is characteristic during drinking and eating (Yoshida, Igarashi, Iwasaki, Fuse, \& Togashi 2015). Three replicates per sample were carried out.

\subsection{Dynamic sensory analysis}

\subsubsection{Wine samples}

A commercial rosé wine ("Matarromera" winery, year 2016) made from Tempranillo and Verdejo grape varieties was used for this study. The chemical compositional was: ethanol $(10 \% v / \mathrm{v}), \mathrm{pH}$ (3.33), protein content $(4892 \pm 303 \mathrm{mg} / \mathrm{l})$, total polyphenols $(208 \pm 12 \mathrm{mg}$ gallic acid/L), procyanidins $(70.5 \pm 1.2 \mathrm{mg}$ catechin/L), neutral polysaccharides $(7379.2 \pm 734.2 \mathrm{mg}$ mannose/L) and free amino acids (185 $\pm 1,6 \mathrm{mg} \mathrm{Leu} / \mathrm{L})$.

To reinforce its aromatic profile, the wine was aromatized with four food grade carboxylic esters (Sigma-Aldrich, Steinheim, Germany): isoamyl acetate (23-92-2), ethyl butanoate (105-54-4), ethyl hexanoate (123-66-0) and ethyl decanoate (110-38-3). All the aroma compounds were added to $15 \mathrm{~mL}$ of wine contained in a glass wine to obtain a final concentration of $60 \mathrm{mg} / \mathrm{L}$, except for ethyl butanoate that was $80 \mathrm{mg} / \mathrm{L}$. These concentrations were much higher than their respective odour thresholds and could be perceived without any difficulty by all the panellists. Aromatisation was individually done (only one aroma compound in each wine glass) and it was performed 5-10 min before the beginning of the sensory evaluation. During this time the wine glasses were covered with plastic Petri dishes to prevent volatile loss.

\subsubsection{Preliminary tests}

Sensory analysis was carried out by the same panellists used for saliva characterisation. Their sensory aptitude (absence of anosmia) was confirmed at the beginning of the study by a triangular test using aromatised hydroalcoholic solutions. In addition, the volunteers received instruction about the protocol to follow with the samples for the retronasal aroma evaluation. To do so, $15 \mathrm{~mL}$ of the aromatised wine were placed into the oral cavity, performing a soft rinsing and spitting the wine out after $30 \mathrm{~s}$. During rinsing, special care was taken to keep the lips closed, not to swallow and not to open the velum-tongue border prior to expectoration. After that, with their lips closed, and after the first swallowing of saliva, they were asked to recognise the retronasal perception.

A consensus in the assignment of aroma descriptors for each of the chemical odorants used to aromatise the wines was reached in the first training session of aroma familiarisation. The final descriptors were "banana" for isoamyl acetate, "pineapple" for ethyl butyrate, "strawberry flavoured sweet "for ethyl hexanoate and "dried plum" for ethyl decanoate.

Volunteers were trained in both, the recognition of the four aroma descriptors in the wine and also in the use of the $15 \mathrm{~cm}$ unstructured scale delimited at the ends. Two different intensities of each attribute, one corresponding to high intensity $(90 \mathrm{mg} / \mathrm{L}$ of each ester) and another one to low intensity ( $30 \mathrm{mg} / \mathrm{L}$ of each ester) were used during training. During these sessions, panellists were told that these concentrations corresponded to high and low intensity of the aroma, respectively. Thirteen training sessions over three months were performed until all panellists were able to recognise all the attributes and to distinguish between high and low aroma intensity.

\subsubsection{Progressive profiling}

After the training, the panellists performed the progressive profiling test (Jack, Piggott, \& Paterson 1994). This is a simple descriptive (qualitative and quantitative) analysis where fixed attributes are rated making their measurements sequential and repetitive at predetermined time points. This technique reduces the cognitive load and needs less training than the Time-Intensity technique (De Lavergne, van Delft, van de Velde, van Boekel, \& Stieger 2015; Galmarini, Symoneaux, Visalli, Zamora, \& Schlich 2016).

To do so, after spitting the wine out, and immediately after the first swallowing of the residual saliva and wine in their mouths keeping their lips closed, panellists scored the perceived intensity of the aroma attributes for an established time. Time points were fixed at 5, 60, 120 and $180 \mathrm{~s}$. Only one aroma attribute was evaluated at a time. Therefore, in the same session, the evaluation was repeated four times, until the evaluation of the four aroma attributes was completed. In each case, the panellists knew the aroma attribute to be evaluated. Data were collected on paper, and attributes were rated by means of a $15 \mathrm{~cm}$ unstructured scale. Each individual using a digital timer measured the intensity at different evaluation times. Between wine samples, panellists rinsed their mouths with tap water and ate some unsalted and nonflavoured breadsticks (MAKRO, Madrid, Spain) to eliminate any traces of aroma. All wine samples (the same wine aromatised with one of the four aroma compounds at each time), were evaluated twice on different days. The order of the samples was randomized in each evaluation session.

\subsection{Data analysis}

One-way ANOVA was used to check the effect of individual on saliva composition and Tukey test was used for mean comparison. Individual data obtained from all the analytical determinations (triplicates) of saliva from the 10 panellists were used for this purpose. Twoway ANOVA was applied to determine the effect of time and panellist in the perceived aroma intensity considering the four tested descriptors. For this, we used the individual intensity data reported for the ten panellists at each time point $(5,60,120$ and $180 \mathrm{~s})$ obtained in two different sensory sessions for the four aroma attributes. Spearman's correlation analysis was used to check the strength and direction of the monotonic relationship between individual saliva composition and the perceived intensity for each tested time $(5,60,120$ and180 s). To do so, an independent test for each time interval using the averaged values of aroma intensity (from two sensory sessions) for each panellist and aroma attributes and the averaged values of saliva composition determined in each individual was used. Linear regression analysis was also applied to to check the strength of the relationship between the perceived retronasal intensity and the most correlated salivary parameters. The analysis was performed with XLSTAT 2017.01.3.

\section{Results and discussion}

\subsection{Inter-individual differences on saliva composition}

In order to determine if saliva composition might influence the perception of specific aromatic stimulus during wine tasting, the chemical composition and rheological properties (viscosity) of the stimulated saliva was determined. Results of saliva composition are shown in Table 1. ANOVA and Tukey test results to check for a significant effect of the individual are also included in Table 1.

As it can be seen in this table, except $\mathrm{pH}, \mathrm{Na}$ and $\mathrm{Zn}$ content, all the salivary parameters were significantly different depending on the individual. On average, the $\mathrm{pH}$ (7.7) could be considered as normal. Values ranging between pH5.3 (low salivary flow) to $\mathrm{pH} 7.8$ (high salivary flow) have previously been reported (Humphrey \& Williamson 2001). The effect of salivary $\mathrm{pH}$ on wine aroma perception seems to be unlikely due to the low amount of saliva in the mouth (above $0.8 \mathrm{~mL}$ ) (Humphrey \& Williamson 2001) compared to the ingested wine (15 mL) that makes that the wine:saliva mixture has a $\mathrm{pH}$ value very close to the wine. On the contrary, salivary flow, showed a large variability. These values ranged between the minimum salivary flow $(1.06 \mathrm{~mL} / \mathrm{min})$ 
Table 1

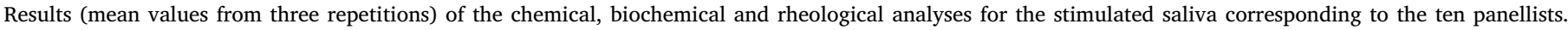
Results from one-way ANOVA and Tukey test are also included in the table.

\begin{tabular}{|c|c|c|c|c|c|c|c|c|c|c|}
\hline \multirow[t]{2}{*}{ Panellist } & Flow & $\mathrm{pH}$ & TPC & $\mathrm{Na}$ & K & $\mathrm{Ca}$ & $\mathrm{Mg}$ & $\mathrm{Zn}$ & $\eta_{50}$ & K \\
\hline & \multicolumn{2}{|l|}{$(\mathrm{mL} / \mathrm{min})$} & $\mathrm{mg} / \mathrm{L}$ & $(\mathrm{mg} / \mathrm{L})$ & $(\mathrm{mg} / \mathrm{L})$ & $(\mathrm{mg} / \mathrm{L})$ & $(\mathrm{mg} / \mathrm{L})$ & $(\mathrm{mg} / \mathrm{L})$ & (Pas) & $\left(\operatorname{Pa~s}^{\mathrm{n}}\right)$ \\
\hline P1 & $1.25^{\mathrm{a}}$ & $7.66^{\mathrm{a}}$ & $839^{\text {cde }}$ & $367^{\mathrm{a}}$ & $890^{\text {abcd }}$ & $176^{\mathrm{bcd}}$ & $14.17^{\mathrm{ab}}$ & $7.27^{\mathrm{a}}$ & $0.0029^{b c}$ & $0.051^{b c}$ \\
\hline P2 & $1.42^{\mathrm{ab}}$ & $7.56^{\mathrm{a}}$ & $564^{\mathrm{ab}}$ & $402^{a}$ & $989^{\text {bcd }}$ & $208^{d}$ & $14.58^{\mathrm{ab}}$ & $8.06^{a}$ & $0.0036^{\mathrm{cd}}$ & $0.067^{\mathrm{cd}}$ \\
\hline P3 & $2.86^{\mathrm{c}}$ & $7.75^{a}$ & $1039^{e}$ & $344^{\mathrm{a}}$ & $745^{\mathrm{ab}}$ & $143^{\mathrm{ab}}$ & $12.50^{\mathrm{ab}}$ & $7.83^{a}$ & $0.0046^{\mathrm{e}}$ & $0.136^{g}$ \\
\hline P4 & $1.31^{\mathrm{a}}$ & $7.47^{\mathrm{a}}$ & $760^{\text {bcd }}$ & $398^{\mathrm{a}}$ & $687^{\mathrm{a}}$ & $156^{\mathrm{abc}}$ & $11.67^{\mathrm{ab}}$ & $8.08^{a}$ & $0.0036^{\mathrm{cd}}$ & 0.079 de \\
\hline P5 & $1.56^{\mathrm{ab}}$ & $7.93^{a}$ & $663^{b c}$ & $381^{a}$ & $880^{\text {abcd }}$ & $136^{\mathrm{ab}}$ & $8.75^{\mathrm{a}}$ & $7.83^{a}$ & $0.0026^{\mathrm{ab}}$ & $0.029^{\mathrm{a}}$ \\
\hline P6 & $2.17^{b c}$ & $7.72^{a}$ & $755^{\text {bcd }}$ & $401^{a}$ & $803^{\mathrm{abc}}$ & $138^{a b}$ & $8.44^{\mathrm{a}}$ & $7.52^{\mathrm{a}}$ & $0.0043^{\text {de }}$ & $0.106^{f}$ \\
\hline P7 & $1.53^{\mathrm{ab}}$ & $7.85^{a}$ & $356^{\mathrm{a}}$ & $400^{a}$ & $751^{\text {ab }}$ & $123^{\mathrm{a}}$ & $8.65^{a}$ & $6.33^{a}$ & $0.0027^{\mathrm{ab}}$ & $0.050^{\text {bc }}$ \\
\hline P8 & $1.39^{\mathrm{ab}}$ & $7.57^{\mathrm{a}}$ & $962^{\text {de }}$ & $351^{\mathrm{a}}$ & $1107^{\mathrm{d}}$ & $162^{\mathrm{abc}}$ & $15.83^{b}$ & $8.02^{a}$ & $0.0021^{a}$ & $0.031^{\mathrm{ab}}$ \\
\hline P9 & $1.06^{\mathrm{a}}$ & $8.00^{a}$ & $2479^{g}$ & $403^{a}$ & $1059^{\mathrm{cd}}$ & $195^{\mathrm{cd}}$ & $16.56^{b}$ & $7.96^{\mathrm{a}}$ & 0.0039 de & $0.090^{\text {ef }}$ \\
\hline $\mathrm{P} 10$ & $2.67^{c}$ & $7.61^{\mathrm{a}}$ & $1322^{f}$ & $367^{\mathrm{a}}$ & $887^{\text {abcd }}$ & $213^{d}$ & $16.04^{b}$ & $7.79^{a}$ & $0.0025^{\mathrm{ab}}$ & $0.031^{\mathrm{ab}}$ \\
\hline Average & 1.72 & 7.71 & 974.34 & 381 & 880 & 165 & 12.72 & 7.67 & 0.0031 & 0.067 \\
\hline \multicolumn{11}{|l|}{ Anova } \\
\hline $\mathrm{F}$ & 13.649 & 0.988 & 184.026 & 2.076 & 6.847 & 15.363 & 5.884 & 2.119 & 25.447 & 79.532 \\
\hline$p>\mathrm{F}$ & $<0.0001$ & 0.479 & $<0.0001$ & 0.083 & $<0.001$ & $<0.0001$ & $<0.001$ & 0.078 & $<0.0001$ & $<0.0001$ \\
\hline
\end{tabular}

TPC: total protein content; $\eta_{50}$ : viscosity at shear rate $50 \mathrm{~s}^{-1} ; K$ : consistency index.

a-e Effect of individual. For each determination, mean values not sharing the same letter with the same column are significantly different $(p<0.05)$.

determined for $\mathrm{P} \# 9$ and the maximum value of $2.86 \mathrm{~mL} / \mathrm{min}$ found for $\mathrm{P} \# 3$ which was more than the double than P\#9. However, the salivary flow values were very close to those previously reported $(1.83 \pm 0.70 \mathrm{~mL} / \mathrm{min}$ ) (Neyraud et al. 2012) using a group of thirteen healthy individuals. The large inter-individual differences in salivary flow are also in agreement with results from previous studies, and they have been related to genetic factors, gender, or age, among others (Fischer et al. 1994; Guinard et al. 1997; Neyraud et al. 2012).

The total protein content (TPC) was also highly dependent on the individual. Their concentration ranged from the lowest value determined for $\mathrm{P} \# 7$ ( $356 \mathrm{mg} / \mathrm{L})$ and the highest determined for $\mathrm{P} \# 9$ $(2479 \mathrm{mg} / \mathrm{L})$. Interestingly, $\mathrm{P} \# 9$ with the highest total saliva protein concentration also showed the lowest salivary flow. An inverse relationship between saliva flow and total protein content in saliva, which could be associated to a dilution phenomenon has been previously observed (Fischer et al. 1994). However, we did not find a relationship between these parameters in this study. Additionally, large inter-individual differences in saliva TPC have also been previously reported in normal (e.g. healthy) populations (Fischer et al. 1994; Guinard et al. 1997; Neyraud et al. 2012). In spite of the wide range of TPC determined in the ten individuals, these values are within the ranges described in the above mentioned works.

Regarding the mineral content, $\mathrm{Na}$ and $\mathrm{Zn}$ were the only minerals that did not show significant differences among individuals. Although very little is known about the role of saliva electrolytes on flavour perception, a relationship between the content of $\mathrm{Na}$ in saliva and the perception of congruent flavours in cheese (salty flavours) has been recently suggested (Guichard et al. 2017). In the case of Zn, it has also been related to enhancing tasting capabilities because of its ability to bind the gustin protein (Humphrey \& Williamson 2001).

For the other minerals ( $\mathrm{K}, \mathrm{Ca}$, and $\mathrm{Mg}$ ), their concentration in saliva was significantly affected by the individuals. $\mathrm{K}$ exhibited the highest concentration from all the minerals determined in the saliva samples. Its concentration ranged between the lowest value determined for panellist P\#4 (687 mg/L) and the highest for P\#8 (1107 mg/L), almost double. Additionally, the concentration of $\mathrm{Ca}$ ranged between the lowest value found in the saliva of $P \# 7(123 \mathrm{mg} / \mathrm{L})$ and the highest value determined in P\#8 and P\#10 (208 and $213 \mathrm{mg} / \mathrm{L}$ respectively). $\mathrm{Mg}$ was found in much lower concentrations compared to the other saliva electrolytes such as $\mathrm{Na}, \mathrm{K}$ or $\mathrm{Ca}$. Its lowest values $(8.44-8.75 \mathrm{mg}$ / L) were determined for $\mathrm{P} \# 6, \mathrm{P} \# 7$ and $\mathrm{P} \# 5$ and the highest values (15.8-16.04 mg/L) for individuals $\mathrm{P} \# 8, \mathrm{P} \# 9$, and $\mathrm{P} \# 10$. In general, individuals with a high concentration of one electrolyte also had elevated concentrations of the other two. An increase in $\mathrm{Na}$ and $\mathrm{Na} / \mathrm{K}$ ratio with an increase in saliva flow, but no changes in $\mathrm{K}$ concentration were previously shown (Prader et al. 2009). Nonetheless, in the present work, individuals with lower salivary flows (e.g. P\#1, P\#4, P\#9) showed a relatively high concentration of electrolytes, while individuals with the highest salivary flows (e.g P\#3) showed a lower electrolyte concentration, which could be due to a higher dilution of these compounds. Many different physiological states might also influence the concentration of saliva minerals. For instance, it has been shown that the concentrations of inorganic components in saliva not only vary according to the saliva secretion rate but also according to the physiological reasons for hyposalivation (Almstâhl \& Wikström 2005). These differences in concentration depending on the individual might also have an effect on wine aroma perception. In fact, these compounds are largely responsible for the ionic strength of saliva (Almstâhl \& Wikström 2005), and therefore, this might have consequences for the partition of aroma compounds in this fluid, which in turn would affect aroma transfer to the exhalation flows and the transport of these odorants to the olfactory receptors.

Finally, the effect of the individuals saliva viscosity was significant at higher shear rates $\left(50 \mathrm{~s}^{-1}\right)$ (Table 1$)$. Viscosity values at $50 \mathrm{~s}^{-1}$ shear rate $\left(\eta_{50}\right)$ are widely deemed relevant for oral evaluation of the texture of liquids (Wagner, Barbati, Engmann, Burbidge, \& McKinley 2017). The $K$ (consistency index), corresponding to the apparent viscosity at a shear rate of $1 \mathrm{~s}^{-1}$ was also considered in this study for comparative purposes. For interpretative purposes, as the value of $K$ increases, the behaviour of the fluid is less Newtonian and more pseudoplastic. As it can be seen in Table 1 , both parameters $\left(\eta_{50}\right.$ and $\left.K\right)$ were significantly affected by the individual $(p<0.0001)$. The $\eta_{50}$ values ranged between the lowest viscosity obtained for $\mathrm{P} \# 8$ (0.0021 Pas) and the highest determined in the saliva for $\mathrm{P} \# 3(0.0046 \mathrm{~Pa} \mathrm{~s})$. In the case of $K$, the values ranged between the lowest for $\mathrm{P} \# 5\left(0.029 \mathrm{~Pa} \mathrm{~s}{ }^{\mathrm{n}}\right)$ and the highest for $\mathrm{P} \# 3\left(0.136 \mathrm{~Pa} \mathrm{~s}^{\mathrm{n}}\right)$. These differences might have an impact on flavour perception, since saliva viscosity might affect the pharyngeal mucosa coating during swallowing and the dynamic aroma profile (De Loubens et al. 2011) and/or the thickness of the salivary coating covering the oropharyngeal mucosa, which in turn might affect aroma dilution after swallowing (Doyennette, De Loubens, Deleris, Souchon, \& Trelea 2011). In spite of its theoretical importance on the behaviour of -in vivo aroma release, as far as the authors know, this saliva property and its effect on aroma perception have not been considered in previous studies. 
Table 2

Retronasal intensity scores for each aroma attribute in the different time points evaluated after wine expectoration.

\begin{tabular}{llllll}
\hline \multirow{2}{*}{ Aroma atribute } & Time $(\mathrm{s})$ & \multicolumn{3}{l}{ Descriptive statistics } & \\
\cline { 3 - 6 } & & Min & Max & Mean & \pm SD \\
\hline \multirow{2}{*}{ Banana } & $5 \mathrm{~s}$ & 3.5 & 15 & 11.4 & 3.73 \\
& $60 \mathrm{~s}$ & 0.6 & 12.3 & 6.28 & 3.90 \\
& $120 \mathrm{~s}$ & 0.0 & 6.3 & 1.93 & 2.24 \\
Pinneapple & $180 \mathrm{~s}$ & 0.0 & 2.3 & 0.42 & 0.73 \\
& $5 \mathrm{~s}$ & 2.8 & 15 & 10.9 & 3.60 \\
& $60 \mathrm{~s}$ & 0.0 & 12 & 6.04 & 3.83 \\
& $120 \mathrm{~s}$ & 0.0 & 5.6 & 2.18 & 2.29 \\
Strawberry & $180 \mathrm{~s}$ & 0.0 & 2.7 & 0.66 & 0.98 \\
& $5 \mathrm{~s}$ & 4.4 & 14.7 & 10.9 & 3.09 \\
& $60 \mathrm{~s}$ & 0.0 & 12.1 & 5.96 & 3.41 \\
& $120 \mathrm{~s}$ & 0.0 & 6.7 & 2.04 & 2.28 \\
Dried Plum & $180 \mathrm{~s}$ & 0.0 & 3.7 & 0.56 & 0.96 \\
& $5 \mathrm{~s}$ & 3.8 & 14.5 & 11.64 & 2.82 \\
& $60 \mathrm{~s}$ & 0.6 & 11.7 & 6.02 & 3.54 \\
& $120 \mathrm{~s}$ & 0.0 & 7.2 & 1.90 & 2.12 \\
& $180 \mathrm{~s}$ & 0.0 & 2.9 & 0.54 & 1.03 \\
\hline
\end{tabular}

Values correspond to the minimum, maximum, mean and standard deviation values of the perceived retronasal intensity provided by the 10 panellists in the two sensory sessions performed in two different days $(\mathrm{N}=20)$ for each attribute and time point).

\subsection{Inter-individual differences in retronasal aroma perception over time}

Progressive profiling was used to check inter-individual differences in the retronasal aroma intensity over time. Table 2 shows the main descriptive statistic values for each aroma attribute at the assayed time intervals. Results corresponded to the minimum, maximum, mean and standard deviation values of the perceived intensity provided by the 10 panellists in the two sensory sessions performed on two different days. At each time interval, a two-way ANOVA was run to evaluate the significance of the considered factors (time and individual) in the perceived intensity of the four aroma attributes. A significant effect $(p<0.0001)$ of both factors and their interactions was found. Fig. 1 shows the interaction graphs (time $\mathrm{x}$ panellist) obtained after the application of this treatment for each aroma attribute. As expected, and as it is shown in Fig. 1 a progressive decrease in the perceived intensity was noticed, which is in agreement with the progressive exhaustion of aroma compounds adhered to the oropharyngeal mucosa due to the sweeping of aroma compounds produced by the exhalation flows in the successive swallowing episodes (Buettner \& Beauchamp 2010). In general, about a 50\%reduction in the retronasal intensity was observed during the first seconds after wine expectoration and above $95 \%$ after $180 \mathrm{~s}$, confirming the low oral persistence of these types of chemical odorants in the mouth after wine rinsing (Esteban-Fernández et al. 2016; Muñoz-González et al. 2019). The reduction in the perceived intensity was very similar among aroma attributes, although the attribute "dried plum" had a higher score and also was the highest rated $180 \mathrm{~s}$ after wine expectoration (Table 2). This could be due to the higher intraoral persistence of ethyl decanoate compared to smaller aliphatic esters (Muñoz-González et al. 2019, Pérez-Jiménez, RochaAlcubilla, \& Pozo-Bayón 2018).

On the other hand, Fig. 1 shows the retronasal aroma intensity scored by each panellist at different times after spitting-off the wine. As it can be seen, large and significant differences in individual perception in the four aroma attributes was noticed. This was also confirmed using the Tukey test (Table S1).

Immediately after wine rinsing and expectoration (Fig. 1), all the panellists retronasally perceived the four attributes; however, large differences among them were observed. For instance, panellist P\#10, $\mathrm{P} \# 2, \mathrm{P} \# 3$ and $\mathrm{P} \# 5$ generally scored higher intensities compared to $\mathrm{P} \# 1$ and $\mathrm{P} \#$ 9, which gave the lowest scores; while $\mathrm{P} \# 7, \mathrm{P} \# 6, \mathrm{P} \# 8$ and $\mathrm{P} \# 4$ gave intermedium intensity values. One minute after wine expectoration (Fig. 1), the overall retronasal intensity decreased for all aroma attributes, but, panellists kept behaving very similar and \#P10, \#P3 and \#P2 always scored higher intensities. In addition, P\#7 also highly scored the attributes "pineapple" and "dried plum", while P\#8 and P\#6 scored the four aroma attributes with medium intensity and P\#5 only the "banana" and "strawberry flavoured sweet" aromas. Once again, P\#1 and P\#9 gave the lowest scores. $120 \mathrm{~s}$ after wine expectoration some individuals did not perceive some attributes anymore (P\#4, $\mathrm{P} \# 1$, $\mathrm{P} \#$ 9). Others (P\#10, $\mathrm{P} \# 3, \mathrm{P} \# 2$ and $\mathrm{P} \# 7$ ) still perceived them quite easily; while a few of them (P\#5 and $\mathrm{P} \# 6$ ) gave very little scores. Finally, $180 \mathrm{~s}$ after spitting-off the wine, only two attributes ("strawberry candy" and "dried plum") were perceived, but only by a few panellists (P\#10, P\#2, P\#3, P\#7 and P\#8), which perceived one or the other. Only $\mathrm{P} \# 10$ perceived both of them.

It seems logical that the longer the time after wine expectoration, there will be lessaroma available for perception and it will be more difficult for the panellists to score the perceived intensity. On the basis of these results, the aroma perception capacity was quite different for each panellist. As previously explained, the higher oral aroma persistence of ethyl decanoate might explain why "dried plum" aroma was still perceived $180 \mathrm{~s}$ after wine expectoration. However, in the case of "strawberry flavoured sweet", this explanation cannot be ruled out on the basis of its hydrophobicity. This attribute was mainly induced in this wines by the addition of ethyl butanoate, which is less hydrophobic than isoamyl acetate or ethyl hexanote (responsible for "banana" and "pineapple" aromas respectively), and therefore, it should have lower aroma persistence. This might suggest that there may not be just one compound (ethyl butanoate) responsible for the "strawberry sweet flavoured" aroma perceived by the panellists.

\subsection{Correlation between saliva composition and individual differences in retronasal aroma perception over time}

If saliva composition affects in-mouth aroma release kinetics after wine intake (Muñoz-González et al. 2019), inter-individual differences in saliva composition might also influence the individual perception of aromas. To check this hypothesis, a Spearman correlation analysis between the saliva compositional parameters (those showing significant differences among individuals) and the perceived retronasal aroma intensity at different times after wine expectoration was carried out. For this treatment, intensity scores obtained $180 \mathrm{~s}$ after wine expectoration were not considered, since most of the panellists did not detect any of the aroma attributes. Results of this analysis are shown in Table 3. From all of the salivary parameters, only the salivary flow showed a strong and positive correlation with the retronasal perception of the four aroma attributes. This correlation was significant for the perceived intensity of the four aroma attributes in the first evaluation time $(5 \mathrm{~s})$, and for "pineapple" and "banana" aromas 60 and $120 \mathrm{~s}$ after wine expectoration (Table 3). Sixty and $120 \mathrm{~s}$ after spitting out the wine, "strawberry flavoured sweet" and "dried plum" aromas no longer showed a significant correlation with salivary flow.

In order to assess the strength of the relationship between the perceived retronasal intensity of the four aroma attributes and the salivary flow, a linear regression analysis was performed with the intensity scores provided at each time interval (except scores from $180 \mathrm{~s}$ which were not considered). Table 4 shows the coefficient of determination $\left(R^{2}\right)$ and the ANOVA results obtained from this analysis. As it can be seen, and considering the $p$ values, salivary flow brings a significant amount of information $(p<.05)$ which can be used to explain the retronasal perceived intensity of most of the aroma attributes ("banana" at 60 and $120 \mathrm{~s}$, "pineapple" at 5 and $60 \mathrm{~s}$ and "strawberry flavoured sweet" aroma at the three tested times). A trend $(p<.1)$ was also observed for "banana" at $5 \mathrm{~s}$, "pineapple" at $120 \mathrm{~s}$, and "dried plum" at $5 \mathrm{~s}$, which could be due to the low number of individuals included in this study, which might have limited the potency of this test to find 

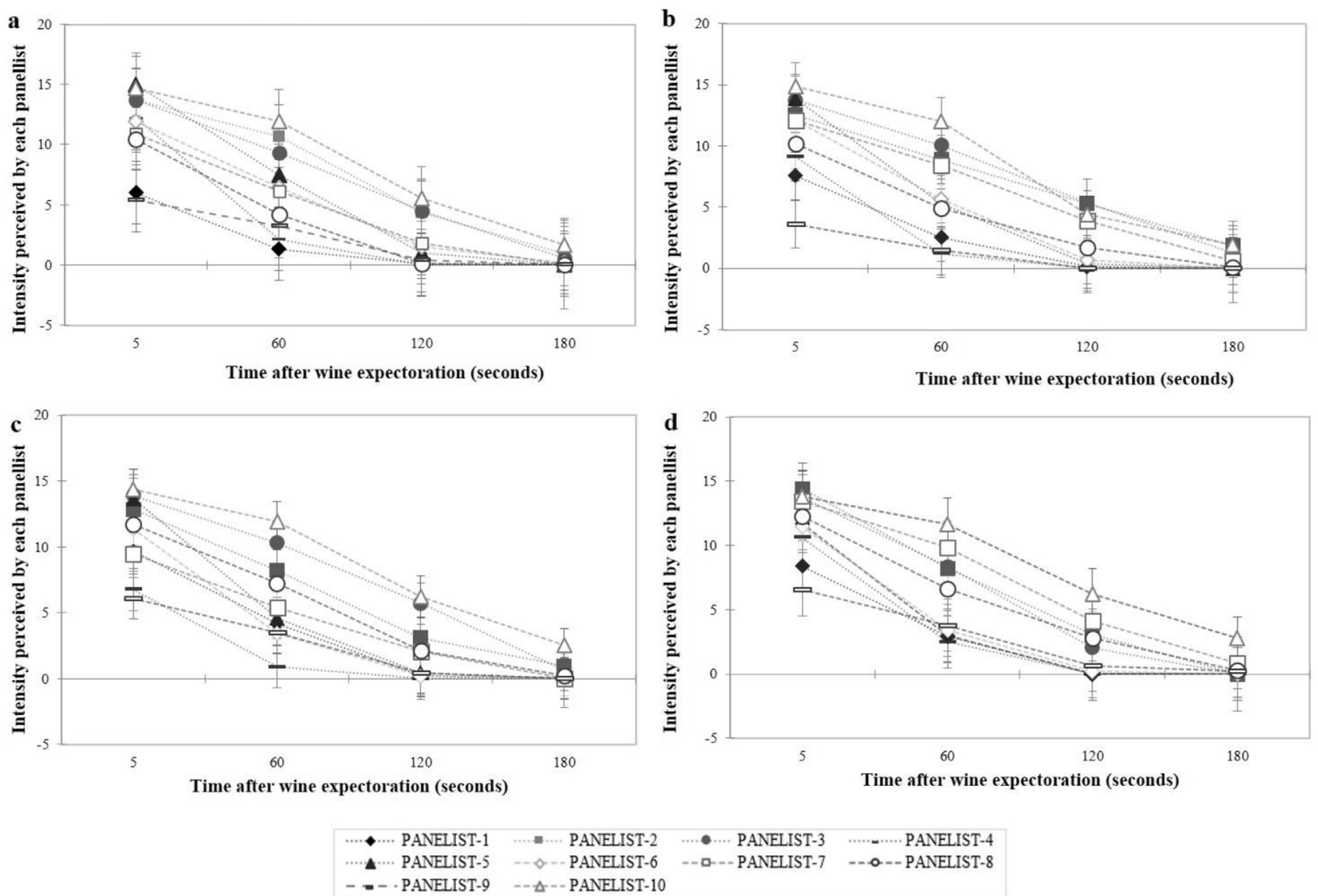

Fig. 1. Retronasal aroma intensity scores for each panellist and time point: (a) "banana", (b) "pineapple", (c) "strawberry flavoured sweet", (d) "dried plum".

differences. Only the attribute "dried plum" at 60 and $120 \mathrm{~s}$ showed a lack of relationship with the salivary flow.

However, in spite of the significant effect of the salivary flow on the retronasal perception of the four aroma attributes, it can only explain between 30 and $60 \%$ of the perceived intensity $\left(R^{2}\right.$ ranged between 0.34 and 0.59). An example of the linear regression model between salivary flow and the perceived intensity of "pineapple" aroma $60 \mathrm{~s}$ after wine expectoration is shown in Fig. 2. Therefore, although saliva flow seems of importance for aroma perception, the remaining variability is probably due to other effects, linked to saliva composition (other salivary compounds) or not (physiological and/or psychological factors) that have not been considered in this study. Fig. 2 shows.

Anyway, these results show that the higher the salivary flow, the higher the retronasal perception of the four aromas attributes, mainly during the first moments after wine expectoration. At longer times after wine expectoration, salivary flow seems to have a higher effect on the aroma attributes like "pineapple", "banana" and "strawberry flavoured sweet" elicited by small esters (ethyl butanoate, isoamyl acetate and ethyl hexanoate), than on "dried plumb" aroma elicited by large esters (ethyl decanoate).

Previously, Guinard and co-workers (Guinard et al. 1997) also showed an effect of salivary flow on the aroma perception of cherry

Table 3

Values from the correlation matrix obtained after the application of the Spearman correlation analysis between salivary parameters and perceived retronasal intensity of aroma attributes rated at different time points after wine expectoration.

\begin{tabular}{|c|c|c|c|c|c|c|c|c|}
\hline \multirow[b]{2}{*}{ Times } & \multirow[b]{2}{*}{ Attributes } & \multicolumn{7}{|c|}{ Salivary parameters } \\
\hline & & Flow & $\mathrm{Ca}$ & $\eta_{50}(\mathrm{~Pa} \mathrm{~s})$ & $K\left(\mathrm{~Pa} \mathrm{~s}^{\mathrm{n}}\right)$ & $\mathrm{Mg}$ & TPC & $\mathrm{K}$ \\
\hline \multirow[t]{4}{*}{$5 \mathrm{~s}$} & Banana & 0.697 & -0.042 & -0.152 & -0.286 & -0.212 & -0.273 & -0.358 \\
\hline & Pineapple & 0.867 & -0.091 & -0.261 & -0.347 & -0.164 & -0.200 & -0.261 \\
\hline & Strawberry flavoured sweet & 0.794 & 0.152 & -0.261 & -0.286 & 0.079 & 0.079 & -0.006 \\
\hline & Dried plum & 0.673 & 0.139 & -0.248 & -0.207 & 0.042 & -0.248 & -0.055 \\
\hline \multirow[t]{4}{*}{$60 \mathrm{~s}$} & Banana & 0.806 & 0.152 & -0.079 & -0.116 & 0.042 & -0.079 & -0.055 \\
\hline & Pineapple & 0.842 & 0.079 & -0.067 & -0.055 & -0.030 & -0.091 & -0.127 \\
\hline & Strawberry flavoured sweet & 0.564 & 0.321 & -0.358 & -0.292 & 0.382 & 0.152 & 0.200 \\
\hline & Dried plum & 0.552 & 0.176 & -0.200 & -0.103 & 0.261 & 0.103 & 0.091 \\
\hline \multirow[t]{4}{*}{$120 \mathrm{~s}$} & Banana & 0.784 & 0.122 & 0.079 & -0.134 & 0.030 & -0.012 & 0.064 \\
\hline & Pineapple & 0.736 & 0.061 & -0.049 & -0.067 & 0.006 & -0.134 & 0.012 \\
\hline & Strawberry flavoured sweet & 0.552 & 0.333 & -0.321 & -0.255 & 0.430 & 0.200 & 0.224 \\
\hline & Dried plum & 0.374 & 0.301 & -0.313 & -0.172 & 0.337 & 0.043 & 0.215 \\
\hline
\end{tabular}

Values in bold are significantly different from zero $(p<0.05)$. TPC: total protein content; $\eta_{50}$ : viscosity at shear rate $50 \mathrm{~s}^{-1} ; K$ : consistency index.

Three independent correlation analyses were run for each time point. The table summarises these results. 
Table 4

Coefficient of determination $\left(\mathrm{R}^{2}\right)$ and ANOVA results $(F, p)$ obtained from linear regression analysis to check the strength of the relationship between the perceived retronasal intensity of the four aroma attributes and the salivary flow in the different time points.

\begin{tabular}{|c|c|c|c|c|c|}
\hline $\begin{array}{l}\text { Time after } \\
\text { expectoration }\end{array}$ & $\begin{array}{l}\text { ANOVA } \\
\text { parameters }\end{array}$ & Banana & Pineapple & $\begin{array}{l}\text { Strawberry } \\
\text { flavoured } \\
\text { sweet }\end{array}$ & Dried plum \\
\hline \multirow[t]{3}{*}{$5 \mathrm{~s}$} & $\mathrm{R}^{2}$ & 0.358 & 0.506 & 0.480 & 0.339 \\
\hline & $F$ & 4.457 & 8.192 & 7.376 & 4.102 \\
\hline & $p>\mathrm{F}$ & $0.068 *$ & $0.021 * *$ & $0.026 * *$ & $0.077^{*}$ \\
\hline \multirow[t]{3}{*}{$60 s$} & $\mathrm{R}^{2}$ & 0.485 & 0.582 & 0.484 & 0.293 \\
\hline & $F$ & 7.546 & 11.155 & 7.515 & 3.321 \\
\hline & $p>\mathrm{F}$ & $0.025^{* *}$ & $0.010^{* * *}$ & $0.025^{* *}$ & 0.106 \\
\hline \multirow[t]{3}{*}{$120 \mathrm{~s}$} & $\mathrm{R}^{2}$ & 0.574 & 0.346 & 0.597 & 0.192 \\
\hline & $F$ & 10.782 & 4.232 & 11.834 & 1.905 \\
\hline & $p>\mathrm{F}$ & $0.011 * *$ & $0.074 *$ & $0.009 * *$ & 0.205 \\
\hline
\end{tabular}

Values in bold are statistically significant: two asterisks $(p<.05)$, one asterisk $(p<.1)$.

aroma using time-intensity analysis. In this work, they only observed an effect of flow on the rate of release from chewing gum, but not on how much (Imax or AUC) or for how long (Tdur). They found that individuals with a high salivary flow took longer to reach the maximum intensity compared to individuals with lower flows. (Mialon \& Ebeler 1997) also showed an effect of salivary flow on aroma release from flavoured water samples. However, in this case, they only observed an effect on an apolar compound such as limonene but not for polar compounds like vanillin. Contrary to that observed in the previous study, in this work, the authors showed that high salivary flow subjects took less time to reach the maximum intensity and for shorter total time, than low salivary flow subjects. More recently, an inverse correlation between unstimulated salivary flow and the AUC (area under the curve) parameter obtained from the in-nose aroma release curves monitored by PTR-Tof-MS after wine expectoration were observed (Muñoz-González et al. 2019). However, this effect was only significant for one of the six assayed aroma compounds (linalool) and only in longer monitoring times (in the 3rd and 4th swallows) corresponding to 180 and $240 \mathrm{~s}$ after wine expectoration.

These apparent conflictive results regarding the effect of salivary flow can be due to the use of very different experimental conditions (whole vs parotid flow; centrifuged saliva or not, type and concentration of aromatic stimuli, different food matrices, etc.). Other factors such as different rates of oral relubrication as well as modifications of the salivary protein profile induced by the adopted experimental conditions could also affect the complex and dynamic reaction medium of the oral environment (Dinnella et al. 2009).

In any case, to understand the effect of salivary flow on the perceived aroma intensity, as shown in the present work, it is necessary to think in the first step of aroma perception. This means the release and transport of aroma compounds from the saliva to the olfactory receptors. During drinking, aroma compounds can be directly released from the wine to the air but also to the saliva and then to the air phase. Partition coefficients between saliva and air determine the quantity of aroma released into the air phase. Moreover, aroma compounds can be also adsorbed onto the mucosal pellicle (Taylor \& Roozen 1996). In the present study, a higher salivary flow was related with a higher perceived aroma intensity. Salivary flow might affect the dynamics of flavour release through different effects. The higher the salivary flow, the higher the dilution of some salivary components such aroma binding proteins. Some saliva proteins can interact with aroma compounds, and specifically with esters through hydrophobic interactions (Pagès-Hélary, Andriot, Guichard, \& Canon 2014). If aroma-protein interactions are reduced, more aroma will be able to reach the olfactory receptors, which might explain why individuals with high salivary flows showed a better perception. In addition, some salivary proteins might have metabolic activity against aroma compounds (MuñozGonzález et al. 2014; Pérez-Jiménez et al. 2018). Therefore, a higher flow might also decrease the amount of aroma metabolizing enzymes, minimising the degradation rate of these compounds and providing more aroma compounds to be transferred to the exhalation flows. Nonetheless, in this work, we did not find an inverse relationship between salivary flow and TPC. The low number of individuals used in this study $(n=10)$, the use of centrifuged saliva that might deplete the content of certain types of proteins (Muñoz-González, Feron, Brulé, \& Canon 2018) or the fact that TPC might not be indicative of the specific aroma binding/metabolic proteins (mucin, $\alpha$-amylase, etc.) (PagèsHélary et al. 2014) could be the reason, and these aspects should be considered in future studies.

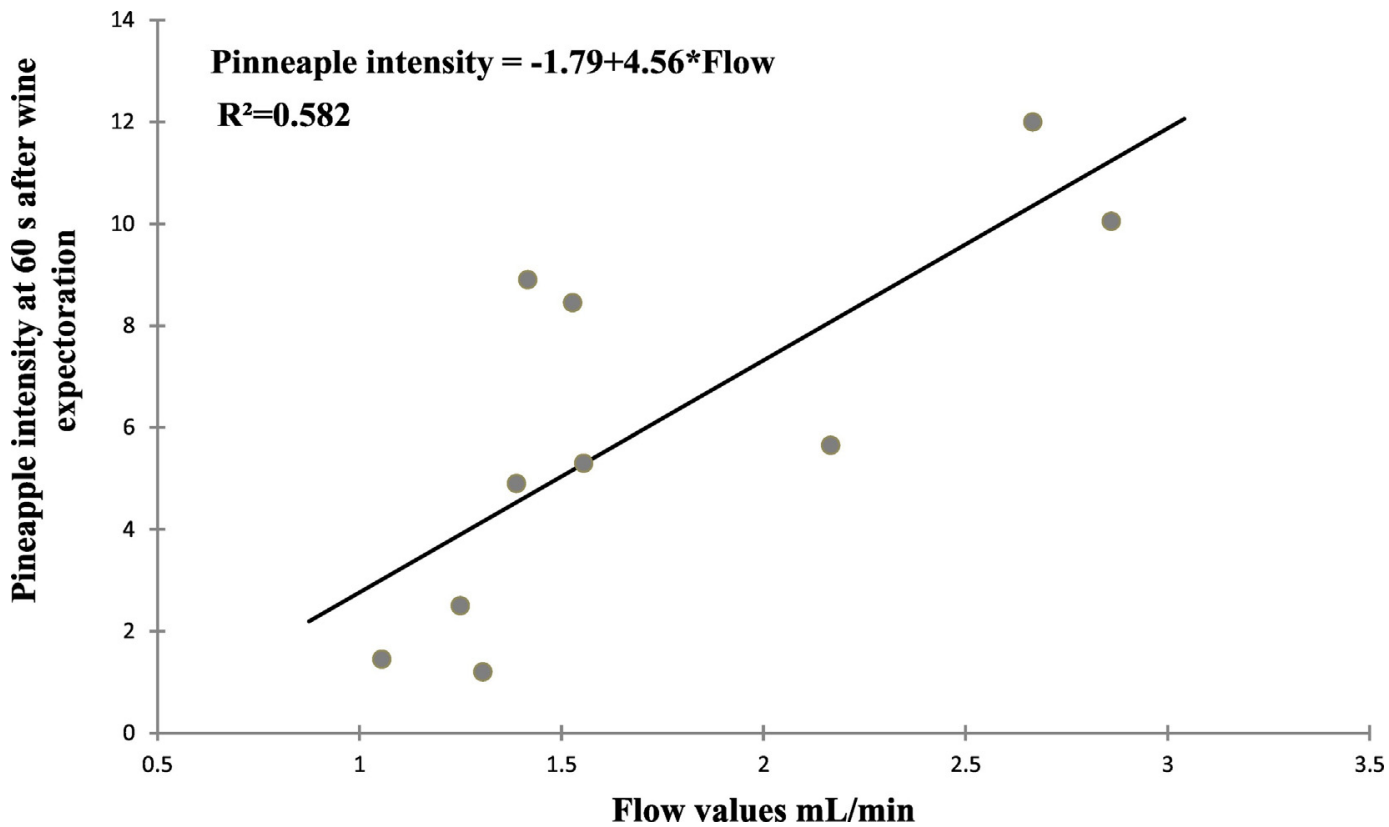

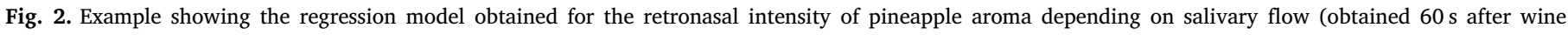
expectoration). 
In addition to the dilution of certain saliva components, an increase in salivary flow might be related to a higher swallowing rate. Once the stimulus (wine) has disappeared from the mouth, there is an amount of saliva that remains in the oral cavity. It is likely that the higher the flow, the higher the remaining saliva in the mouth will be and thus, the higher the number of involuntary swallowing episodes for mouth clearance. In fact, during the intensity evaluation over time, swallowing was not controlled by the volunteers. As a consequence, a higher number of swallowing breaths transporting aroma compounds to the olfactory receptors might have led to a greater release of aroma. In this case, aroma release should be higher immediately after wine expectoration than later ( $60 \mathrm{~s}-180 \mathrm{~s}$ ). At longer times after spitting out the wine, exhaustion of the aroma molecules in the mouth headspace and/ or of the aromas adsorbed to the oral and pharyngeal mucosa as a consequence of the sweeping exerted by exhalation flows is expected. Since partition coefficients between saliva and air should control the quantity of aroma released into the air phase in each swallowing event, it is likely that the most volatile and less hydrophobic esters were released more quickly than the less volatile and hydrophobic ones (Esteban-Fernández et al. 2016; Perez-Jiménez et al. 2019). This might explain the lack of correlation between salivary flow and the perception of the aroma stimuli ("dried plum") elicited by large esters such as ethyl decanoate.

\section{Conclusion}

Strong evidence supports the effect of salivary flow rate on the perception of the aroma intensity over time elicited by esters after wine intake. This effect could be due to the effect of salivary flow on the physicochemical processes behind the dynamics of -in vivo aroma release. Salivary flow seems to have a greater effect on the immediate than the long lasting perception, and on aroma attributes ("banana", "strawberry flavoured sweet" "pineapple") elicited by short chain length esters (isoamyl acetate, ethyl butanoate and ethyl hexanoate", than in the case of "dried plum" elicited by longer chain esters (ethyl decanoate). However, more research is needed to confirm this relationship with larger number of subjects and other dynamic methods that use a continuous evaluation of the perceived intensity rather than discrete time points. For instance, in future works, a Time-Intensity method would be advisable and also to control the amount of swallowing while recording the dynamics of perception. In addition, besides of the effect of saliva, the coexistence of other physiological and/or psychological factors, such as perceptual interactions (synergistic/antagonism odour-odour or odour-taste effects) may also have an influence on the dynamics of aroma But, overall, these results provide important findings on the role of saliva in wine aroma perception, which should be considered for a better understanding of consumer's behaviour and wine choices.

Supplementary data to this article can be found online at https:// doi.org/10.1016/j.foodres.2019.108677.

\section{Funding}

This work was supported by the Spanish Ministry of Economy and Competitiveness (Project AGL2016-78936-R), (AEI/FEDER, UE).

\section{Declaration of Competing Interest}

Authors declare they do not have any conflict of interest.

\section{Acknowledgments}

Authors greatly thank all the volunteers that participated in this study and the technical assistance of M. Pérez-Jiménez in some saliva analysis.

\section{References}

Almstâhl, A., \& Wikström, M. (2005). Microflora in oral ecosystems in subjects with hyposalivation due to medicines or of unknown origin. Oral Health \& Preventive Dentistry, 3, 2.

Buettner, A., \& Beauchamp, J. (2010). Chemical input-Sensory output: Diverse modes of physiology-flavour interaction. Food Quality and Preference, 21(8), 915-924.

Buettner, A., Beer, A., Hannig, C., \& Settles, M. (2001). Observation of the swallowing process by application of videofluoroscopy and real-time magnetic resonance imaging-Consequences for retronasal aroma stimulation. Chemical Senses, 26(9), 1211-1219.

Canon, F., Neiers, F., \& Guichard, E. (2018). Saliva and flavor perception: Perspectives. Journal of Agricultural and Food Chemistry, 66(30), 7873-7879.

De Lavergne, M. D., van Delft, M., van de Velde, F., van Boekel, M. A., \& Stieger, M. (2015). Dynamic texture perception and oral processing of semi-solid food gels: Part 1: Comparison between QDA, progressive profiling and TDS. Food Hydrocolloids, 43, 207-217.

De Loubens, C., Saint-Eve, A., Déléris, I., Panouillé, M., Doyennette, M., Tréléa, I. C., \& Souchon, I. (2011). Mechanistic model to understand in vivo salt release and perception during the consumption of dairy gels. Journal of Agricultural and Food Chemistry, 59(6), 2534-2542.

Dinnella, C., Recchia, A., Fia, G., Bertuccioli, M., \& Monteleone, E. (2009). Saliva characteristics and individual sensitivity to phenolic astringent stimuli. Chemical Senses, 34(4), 295-304.

Doyennette, M., De Loubens, C., Deleris, I., Souchon, I., \& Trelea, I.-C. (2011). Mechanisms explaining the role of viscosity and post-deglutitive pharyngeal residue on in vivo aroma release: A combined experimental and modeling study. Food Chemistry, 128(2), 380-390.

Escudero, A., Campo, E., Fariña, L., Cacho, J., \& Ferreira, V. (2007). Analytical characterization of the aroma of five premium red wines. Insights into the role of odor families and the concept of fruitiness of wines. Journal of Agricultural and Food Chemistry, 55(11), 4501-4510.

Esteban-Fernández, A., Rocha-Alcubilla, N., Muñoz-González, C., Moreno-Arribas, M. V., \& Pozo-Bayón, M. (2016). Intra-oral adsorption and release of aroma compounds following in-mouth wine exposure. Food Chemistry, 205, 280-288.

Fischer, U., Boulton, R., \& Noble, A. (1994). Physiological factors contributing to the variability of sensory assessments: Relationship between salivary flow rate and temporal perception of gustatory stimuli. Food Quality and Preference, 5(1-2), 55-64.

Francis, I., \& Newton, J. (2005). Determining wine aroma from compositional data. Australian Journal of Grape and Wine Research, 11(2), 114-126.

Galmarini, M., Symoneaux, R., Visalli, M., Zamora, M., \& Schlich, P. (2016). Could time-intensity by a trained panel be replaced with a progressive profile done by consumers? A case on chewing-gum. Food Quality and Preference, 48, 274-282.

Genovese, A., Piombino, P., Gambuti, A., \& Moio, L. (2009). Simulation of retronasal aroma of white and red wine in a model mouth system. Investigating the influence of saliva on volatile compound concentrations. Food Chemistry, 114(1), 100-107.

Guichard, E., Repoux, M., Qannari, E., Labouré, H., \& Feron, G. (2017). Model cheese aroma perception is explained not only by in vivo aroma release but also by salivary composition and oral processing parameters. Food \& Function, 8(2), 615-628.

Guinard, J. X., Zoumas-Morse, C., Mori, L., Uatoni, B., Panyam, D., \& Kilara, A. (1997). Sugar and fat effects on sensory properties of ice cream. Journal of Food Science, 62(5), 1087-1094.

Humphrey, S. P., \& Williamson, R. T. (2001). A review of saliva: Normal composition, flow, and function. The Journal of Prosthetic Dentistry, 85(2), 162-169.

Jack, F. R., Piggott, J. R., \& Paterson, A. (1994). Analysis of textural changes in hard cheese during mastication by progressive profiling. Journal of Food Science, 59(3), $539-543$.

Linforth, M., \& Carey, D. T. (2002). Retronasal transport of aroma compounds. Journal of Agricultural and Food Chemistry, 50(5), 1111-1117.

Mialon, V. S., \& Ebeler, S. E. (1997). Time-intensity measurement of matrix effects on retronasal aroma perception. Journal of Sensory Studies, 12(4), 303-316.

Muñoz-González, C., Canon, F., Feron, G., Guichard, E., \& Pozo-Bayón, M. A. (2019). Assessment wine aroma persistence by using an in vivo PTR-ToF-MS approach and its relationship with salivary parameters. Molecules, 24(7), 1277.

Muñoz-González, C., Feron, G., Brulé, M., \& Canon, F. (2018). Understanding the release and metabolism of aroma compounds using micro-volume saliva samples by ex vivo approaches. Food Chemistry, 240, 275-285.

Muñoz-González, C., Feron, G., Guichard, E., Rodríguez-Bencomo, J. J., Martin-Alvarez, P. J., Moreno-Arribas, M. V., \& Pozo-Bayón, M. A. N. (2014). Understanding the role of saliva in aroma release from wine by using static and dynamic headspace conditions. Journal of Agricultural and Food Chemistry, 62(33), 8274-8288.

Muñoz-González, C., Vandenberghe-Descamps, M., Feron, G., Canon, F., Labouré, H., \& Sulmont-Rossé, C. (2018). Association between salivary hypofunction and food consumption in the elderlies. A systematic literature review. The Journal of Nutrition, Health \& Aging, 22(3), 407-419.

Neyraud, E., Palicki, O., Schwartz, C., Nicklaus, S., \& Feron, G. (2012). Variability of human saliva composition: Possible relationships with fat perception and liking. Archives of Oral Biology, 57(5), 556-566.

Pagès-Hélary, S., Andriot, I., Guichard, E., \& Canon, F. (2014). Retention effect of human saliva on aroma release and respective contribution of salivary mucin and $\alpha$-amylase. Food Research International, 64, 424-431.

Perez-Jiménez, M., Chaya, C., \& Pozo-Bayón, M. (2019). Individual differences and effect of phenolic compounds in the immediate and prolonged in-mouth aroma release and retronasal aroma intensity during wine tasting. Food Chemistry, 285, 147-155.

Pérez-Jiménez, M., Rocha-Alcubilla, N., \& Pozo-Bayón, M. (2018). Effect of saliva esterase 
activity on ester solutions and possible consequences for the in-mouth ester release during wine intake. Journal of Texture Studies, 50, 62-70.

Ployon, S., Morzel, M., \& Canon, F. (2017). The role of saliva in aroma release and perception. Food Chemistry, 226, 212-220.

Prader, A., Gautier, E., Gautier, R., Naf, D., Semer, J. M., \& Rothschild, E. (2009). The Na and $\mathrm{K}$ concentration in mixed saliva: Influence of secretion rate, stimulation, method of collection, age, sex, time of day and adrenocortical activity. The human adrenal cortex (pp. 382). .

Rapp, A., \& Mandery, H. (1986). Wine aroma. Experientia, 42(8), 873-884.

Ruiz-Rodríguez, B.-M., Morales, P., Fernández-Ruiz, V., Sánchez-Mata, M.-C., Camara, M., Díez-Marqués, C., ... Tardío, J. (2011). Valorization of wild strawberry-tree fruits
(Arbutus unedo L.) through nutritional assessment and natural production data. Food Research International, 44(5), 1244-1253.

Taylor, A. J., \& Roozen, J. (1996). Volatile flavor release from foods during eating. Critical Reviews in Food Science and Nutrition, 36(8), 765-784.

Wagner, C. E., Barbati, A. C., Engmann, J., Burbidge, A. S., \& McKinley, G. H. (2017). Quantifying the consistency and rheology of liquid foods using fractional calculus. Food Hydrocolloids, 69, 242-254.

Yoshida, M., Igarashi, H., Iwasaki, K., Fuse, S., \& Togashi, A. (2015). Evaluation of viscosity of non-newtonian liquid foods with a flow tube instrument. International Journal of Food Engineering, 11(6), 815-823. 